Résumés des conférences et travaux

\title{
Histoire du droit public de la fin de l'Ancien Régime à nos jours
}

\section{François Monnier}

\section{(2) OpenEdition}

\section{Journals}

Édition électronique

URL : https://journals.openedition.org/ashp/1027

DOI : $10.4000 /$ ashp. 1027

ISSN : 1969-6310

\section{Éditeur}

Publications de l'École Pratique des Hautes Études

\section{Édition imprimée}

Date de publication : 2 février 2011

Pagination : 258-259

ISSN : 0766-0677

\section{Référence électronique}

Francois Monnier, « Histoire du droit public de la fin de l'Ancien Régime à nos jours », Annuaire de I'École pratique des hautes études (EPHE), Section des sciences historiques et philologiques [En ligne], 141 | 2011, mis en ligne le 24 février 2011, consulté le 06 juillet 2021. URL : http:// journals.openedition.org/ashp/1027 ; DOI : https://doi.org/10.4000/ashp.1027 


\title{
HISTOIRE DU DROIT PUBLIC DE LA FIN DE L'ANCIEN RÉGIME À NOS JOURS
}

\author{
Directeur d'études : M. François MonNiER
}

Programme de l'année 2008-2009 : Le Conseiller d'Estat ou Recueil général de la politique moderne, de Philippe de Béthune (suite).

On a terminé l'établissement complet et l'annotation des trois parties du texte du Conseiller d'État de Philippe de Béthune, ce qui n'a pas été sans poser certaines difficultés en raison du caractère sibyllin ou fantaisiste de la quasi totalité de ses citations, incluses dans ses développements sans que rien ne les signale selon les habitudes de l'époque, ce qui a fait l'objet des travaux de la première heure hebdomadaire de la conférence.

La seconde heure a été consacrée à chercher ce qu'il est possible de comprendre aujourd'hui d'un texte qui a été établi au début du XVII ${ }^{\mathrm{e}}$ siècle, en évitant évidemment, dans le mesure du possible, les pièges de l'anachronisme et des détournements d'interprétation. Béthune a vécu à Rome, il a voyagé en Écosse, en Allemagne, en Italie, en Suisse et dans la province française; il connaît la littérature italienne, espagnole, probablement anglaise; il a une expérience personnelle de la politique, et s'il n'en fait guère état, c'est tout de même le socle de son livre; il se garde bien aussi de dire ce qui déplaît à Richelieu... Alors, dans tous ces mélanges, au milieu de toutes ces influences, que pense-t-il vraiment? Il écrit principalement par expérience. Mais pas toujours, car il se sert visiblement aussi de ses lectures (Commynes, Machiavel, Guichardin, Villars, Jeannin, le cardinal d'Ossat, Bacon, Balzac, Silhon, etc., mais aussi les auteurs et historiens latins, Hérodote, Thucydide, Xénophon, Polybe, Cicéron, César, Salluste, Tite-Live, Plutarque, Tacite, auxquels il se réfère en permanence, sans jamais les citer). C'est d'autant plus difficile à dire qu'il se cache en partie, qu'il se méfie de la censure, qu'il cherche à l'endormir et qu'il ne veut pas déplaire à ses amis et à ses protecteurs. Beaucoup de ce qu'il écrit est en trompe l'œil... Il est dans la « Realpolitik ». Il se sert aussi de certaines notions juridiques, mais ce n'est visiblement pas un juriste, ses notions de droit, de normes juridiques ou morales sont loin d'être au point, elles sont en tout cas bien loin de ce qu'elles sont devenues aujourd'hui. Il récuse aussi le monde de la scolastique de saint Thomas, tout comme un Descartes. La politique est pour lui, par construction, une expérience, elle varie suivant les circonstances, d'où un refus marqué de la tradition normative et nominaliste : le droit, les institutions, reflets de Dieu. On ne peut le comparer à Charron, à Balzac ou à Silhon, car ces auteurs n'avaient aucune responsabilité politique : on a affaire à un joyau à part. On voit ainsi la difficulté de « comprendre » un tel livre, d'autant que l'on n'a pas le manuscrit original, que l'on ne connaît pas l'équipe qui l'entourait, alors qu'il a eu nécessairement 
des secrétaires, on ne connaît rien non plus de la genèse de l'ouvrage, on en est réduit à des hypothèses, on ignore également la version « probablement » soumise à Richelieu, tout comme les observations que celui-ci n'a pas manqué de formuler, comme on ne sait pas non plus pourquoi le livre a été immédiatement lu en Angleterre (on a la traduction à la Nationale et au British Museum).

On a cherché, enfin, à dégager les idées principales du livre, qui tiennent au fonds commun des auteurs de l'époque, dans la mesure où Béthune n'est pas un penseur original : son exaltation d'un État en pleine construction, son effort pour le dégager du fait religieux, tout en le subordonnant à la morale catholique, sa défense du mercantilisme en matière économique, ses idées sur le développement urbain, son populationnisme, son plaidoyer pour une marine puissante, sa justification des entreprises coloniales, ses développements sur l'indépendance absolue dont doit jouir le prince ou sur l'indivisibilité du pouvoir, ses tirades contre la féodalité, sa défense résolue de la société d'ordres, son souci du repos public, son aversion pour la vénalité des offices et, évidemment, ses développements sur la raison d'État. Pour autant, ses variations personnelles sur ce fonds commun laissent paraître une véritable personnalité, qui ne manque pas d'originalité et d'intelligence ni de réelles convictions. 